\title{
Methodological Issues in the Research of Nomination in Artificial Languages
}

\author{
Sergey K. Cherepanov a** and Yuri P. Rogovoi ${ }^{\mathrm{b}}$ \\ ${ }^{a}$ Siberian Federal University \\ 79 Svobodny, Krasnoyarsk, 660041, Russia \\ ${ }^{b}$ St. Petersburg State University \\ of Information Technologies, Mechanics and Optics \\ 49 Kronverksky, St. Petersburg, 197101, Russia
}

Received 25.06.2014, received in revised form 17.09.2014, accepted 24.09.2014

This article introduces the conception of the preintelletual state of the language in the form of spontaneous individual saundcreation (lettercreation) on the basis of the differential notions of "language" and "the form of thought. On the assumption of language evolution conception in the direction of limitation individual spontaneous language creation with the help of the norms of language behavior, we describe the variant of logic explication of such an evolution. We also formulate the methodological principles of possible of such a logical explication. It could be seen as "theory of naming".

Keywords: artificial language, preintellectual state of language's evolution, lettercreation, logical explication, individual spontaneous language creation, "theory of naming".

Research area: philosophy.

Problem discourse. To what degree are so often discussed artificial languages (ALs) indeed languages? What is the relationship between the concept of the AL and the traditional notions of language and forms of thought? What is the future of the logical theory of names? The present article will seek to answer these and related issues.

It is common knowledge that any language is a living and breathing audial creation that does not have any apriori limitations. The form of thought is associated with stable language constructs, which can be assembled and disassembled in accordance with certain rules into components (elementary forms). In traditional logic notions were seen as elementary forms, and judgments and conclusions - as complex forms. In contemporary mathematical logic nominals are considered indefinite language constructs, consisting of simple letter symbols (comprising the alphabet). Nominals represent object idenitification acts, and differences across nominals reflect the continuous and varied nature of our reality, which exists independently of human beings' cognitive activity.

Structural linguistics sets parallels between cognition and language structures: subjects, predicates, objects, attributes, etc. (Laguta, 2007). Understandably, grammar of any language

(C) Siberian Federal University. All rights reserved

* Corresponding author E-mail address: sksk52@mail.ru 
is no more than an effort to structure subjective activities, in the end, structuring the meaning into nominal components (nouns, verbs, pronouns, etc.) The phenomenon of "sensemaking" is factored out, and the question of how meaningful structures arise form the combination of morphological insignificant "atoms", ie letters or sounds, is not analyzed in logic.

Using the AL notion allows to deepen the limits of structuring cognition (as compared to traditional logic) by separating individual nominals and notions (constants and variables). As soon as the first step of building an AL begins, a subconscious substitution of notions takes place. The usual standard phrase goes: "Let $\mathrm{x}, \mathrm{y}$... represent variables in some subject area." Let us ask ourselves, for what reason do we call graphic representations of letters "variables"? What does this word mean? And what is the difference between the graphic representation of variables and the graphic representation of constants (values of variables)? We will get no clear answer, of course. We will be told that letter "a" can be the value of the variable " $\mathrm{x}$ " if $a \in X$, where $X$ is the subject area for $\mathrm{x}, \mathrm{y}$.... Such an explanation is an example of explaining the unknown through the incomprehensible. The word combination "variable value» is as unclear as the notion of the variable itself: both are represented as letters (signs). And should we ask what a letter (sign) is, we risk hearing something like: a sign is a sign!

A modern logician has been used to maneuvering around uncomfortable questions. For him or her the notion of the AL is a variant of a modernized notion of form; others will decide for him or her what the essence of that modernization is, and what questions it can help solve. Let us consider in this problem context the standard procedure for introducing the notion of form of thought through arithmetic operations. Let's take an example of commutative summation: 7 $+3=3+7 ; 5+2=2+5$, etc. The standard procedure for generating forms of these proposals is to disavow the names of specific numbers and introduce a common notation for all such cases: $\ldots+\ldots=\ldots+\ldots$ Following this, a key condition becomes that for the notion of form of thought to become fully valid, the empty spaces should be filled with variables, or variables and constants. After this, the following notation appears: $\mathrm{x}+\mathrm{y}=\mathrm{y}+\mathrm{x}, 0+\mathrm{x}=\mathrm{x}+0$, etc. Letters replacing the empty places are declared variables; while numbers, the names of which can be substituted instead of variables become values of these variables. It should be noted that the original form of a notation with empty spaces does not reflect any laws of "the world of numbers": unless you know in advance what the original equations were, it is difficult to guess what empty spaces must be filled with the same names of numbers or the same variables.

This example shows us that the category of the variable is based on the fact of existence of a certain subject area that we should like to discuss in some detail. Our thinking does not impose any restrictions on the nature of the subject area. You can think about anything. However, the concept of universal explanations for any subject area is highly vulnerable. To discredit it, one question would suffice: can subjectlessness become a subject of logical thinking? Since we do not find it difficult to attach - lessness to the notion of "subject," we shall assume we think of subjectlessness no worse than of its antonym. However, thinking about the absent subject of thought is the same as to think about nothing. It is well known that you cannot think about nothing. Therefore, one should move away from those a priori notions that anything can become an object of thought, and somehow amend them.

Therefore, we will have to reconsider the phenomenon of "intellectual permissiveness." Without abandoning the thesis of the autonomy 
of thought and the creative character of thinking (which not only reflects the world but creates it, too) we must then specifically explain the cases of thoughts getting into "linguistic traps," exposing their extreme dependence on language. The latter does not really fit in with the notion of language being "a docile instrument" of thought.

The attempts of some scholars to rely on conceptual interpretation of the notion of language (language theory) without reference to these problematic issues, within which it can be quite effective, seem fairly dubious against the background of the aforesaid.

Unfortunately, enthusiasts of "artificial language" construction do not seem to be able to explain what model of relationship between language and thought (language and the form of thought) they adhere to in their projects. Structural linguists also experience some difficulty. Understandably, any sphere of inquiry needs its own classification domain, since having such a classification leads to identification of some form of data structure. But not even linguists themselves understand why linguistic activity is forced to fit into the structuralist doctrine: for what important problems, for discovery of which new horizons?

This situation is not unique. The science of physics finds itself in the same predicament when forced to address the topic of waveparticle dualism of microscopic objects. In the context of different objectives experimenting may take a variety of forms, conditional on the choice of a particular model of a microscopic object. But then the question of how things really stand is rejected as un-scientific because it addresses neither the instrumental resources nor the scale of the problem. For physics the problem becomes to conceptualize the distinction between experimental results documenting both wave and corpuscular properties of microscopic objects, without mixing them together. Similarly, linguists find themselves having to conceptualize the differentiated approach to their domain. This requires not only using centuries of experience to differentiate between kinds of names by means of which the domain is described (without mixing variables and constants), but to be able to explain the very fact of this differentiation and suggest a logical model to this end. This is a new and nontrivial problem for the science of logic.

It is a well-known fact that persistent attempts to reconstruct the specifics of names themselves (individual concepts) have not yielded any results. Russell thought a lot of linguistic realities and eventually created the theory of descriptions (Russell,1905). Description is the analogue of definiens in the structure of nominal definition. Kripke attempted to explicate the idea of denotation using semantic conception of possible worlds (Kripke,1980). Field (Field,1973), Dummett (Dummett, 1976), Dennett (Dennet, 1991) and others have tried to make the correlation of truth and denotation more transparent, but not very successfully. Some researchers (Kuslii, 2009) argue that the theory of descriptions and Kripke's conception should not be opposed. It seems to us that some considerable methodological innovations should be done.

\section{Informative naming. The principles} of theoretical language nomination. We should not always proceed from the object domain existence, i.e. individual names, and consider the implementation of variables as a generalization of the latter. Naturally, to appeal to the phenomenon of variables considering it as a synonym of initial indefinite (changeable) nature of all things. Secondly, consider constants as being separate cases of variables (temporary absence of variability). The act of naming within this consideration becomes an act of reducing uncertainty (obscurity), i.e. an act of cognition. This is just what it had been considered at the dawn of cognition. 
Understandably, a transfer from $\mathrm{x}$ to $\mathrm{a}$ is far from being a primitive procedure associated with the act of substitution $\mathrm{x} / \mathrm{a}$ due to condition $\mathrm{a} \in \mathrm{X}$. This naming act has no informative value, and its structure is represented as tautology $a \rightarrow(x \rightarrow a)$. Let us not also that this tautology is associated with the effect of uncertainty of new knowledge, as described in one of Socratic dialogues by Plato. In the dialogue Plato says, for instance, that nothing new can be found because you cannot find something who no one knows of. Consequently, whatever's found cannot be new: only known things are discovered.

The «permutational» version of naming serves a great illustration of the aforementioned concept of impossibility of new knowledge. The transfer from $\mathrm{X}$ to a carries no new information since «a» has been known beforehand. Such is the dogma of structuralism, vulnerable due to the imperceptible for amateurs substitution of the notion of knowledge with a more precise notion of the form of thought.

Much has been said about the inadequate nature of structuralist paradigm in the study of language. Let me quote here from Hintikka, a renowned scholar of logic. "The case is that honed conceptual tools available to modern logic and philosophy are adapted to deal with the analysis of established structures - structure of scientific theories, for example, rather than with some kind of activity by means of which these structures were created. In contemporary analytic philosophy there is no transcendental point of view, focused on human activity underlying the acquisition of any information.One-sidedness in the logical analysis of language corresponds to the one-sidedness of epistemic interests (and to some extent it is the cause of it). Correlation between the language and the reality is either not analyzed, or is expressed in non-axiomatized terms, such as «naming attitude», «interpretation» etc.”(Hintikka, p.92).
To avoid such simplification we will introduce two new methodological principles that we will refer to as the "principle of non-self sameness» (NSS) and the «principle of objectified activity dualism «(OAD) . To describe the former we need to stress that the most primitive act of naming is the act of self-creating a «sign,» a kind of created reality. A sign is an object of a special kind, it cannot be identified with the traditional object of cognition.

What is the main outstanding feature of the object of cognition? We would like to quote here profound thoughts of Slovak mathematician P. Vopenka, who studied analysis of cognitive tenets. «Of key importance for our worldview is the principle of the object's self-identity. It is on that premise that we base our confidence in that the world can be a starting point of our learning; both as a constant and a variable. Anything that changes does that while retaining its essence..." (Vopenka, p.18)

Logicians, introducing the symbols of variables and constants, call them subjects, but in their thoughts they liken them to objects, the essence of self-identity. Von Wright: «I believe that the word can be viewed as some kind of an object. Each word, for instance, consists of a certain number of letters or syllables (Wrigt, p.450). However, not everything that can be formally represented can be identified with objects. Speech acts are not objects, words are not simply collections of letters, they have their essence, their meaning. Sign construction mean more for someone than just their material, external representation. A sign is an essence that cannot be self-identical. Therefore, all efforts «to introduce as common as notion of sign as possible had encountered considerable logical and epistemological difficulties that no one has overcome so far" (Levin, p.96).

We believe that non-self-identical essences that signs are can be handled correctly. As we 
confirm that variable $\mathrm{x}$ is different from other variable $-\mathrm{y}, \mathrm{z}, \mathrm{t} .$. , we do not preclude the fact that $\mathrm{x}$ means a, i.e. $\mathrm{x}=\mathrm{a}$. The problem is that the difference of $x$ from other variables with selfidentifiable $\mathrm{x}(\mathrm{x}=\mathrm{x})$ should not be interpreted as an alternative to $\mathrm{x}=\mathrm{a}$. For this to be true, we must agree that the constant (i.e. a) is a particular case of a variable (i.e. $x$ ). In other words, absence of change is a variety of changeableness (rest is a case of motion). Then there are some difficulties, too. An empty glass could be viewed as alternative to a half-empty glass. So in order to implement the noncontradictory hypothesis of unity of constants and variables we will need to construct the so-called computation of satisfiable formulas, and then show that it has a noncontradictory true model in logic of the first order.

Let us now proceed to considering the principle of objectified activity dualism. First let us note that it has two sides. One is the principle of continuation: it views language not as a structure for denoting something with think about and therefore view it as a subject of thought; instead it considers language to be a sort of continuing bodily activity that takes the form of production of sounds and interaction between the body and the environment. The sounds are individual; any likeness between them has spontaneous character. Anthroposociogenesis leads to appearance of superindividual skills of sound production - unity of speaking patterns. This is the second part of this principle $(\mathrm{OAD})$ that we will call language socialization.

According to OAD we may not distinguish the sounds and the act of their production, since the language is the inseparable unity of the process and the result. Let us denote the initial stage of the language element, which is characteristic for the pre-social stage of language functioning by letter «U» (for «uncertainty»). Let us imitate the $\mathrm{U}$ by writing down words (chains of letters) consisting of the some finite number of combinations. The act of attaching letters (forming a word) does not depend on the type of letters or words - it is arbitrary. Words, or chains of letters of some finite length, are separated from each other with empty spaces (empty words). This emptiness informs the physiological act of inhaling (adding more ink, etc.).

Therefore, logically, we can conceive of two possible variants of continuing conversations: creating (1) and iterating (2). In the end, we arrive at the situation that allows to advance the images of propositional letters from the future: $p, q, r$ ..., and interpret them as representing options (1) or (2). We will then use the symbol "I" as a shortened version of the situation of iteration, as a synonym of expressing one and the same something (letter). We will associate the symbol " $\mathrm{H}$ " with the situation of creation, i.e. constituting something different from the earlier actualized speech act. Therefore, the sequence of pp will be a separate case of iteration (I), and the sequence of $p q-a$ separate case of creation $(\mathrm{H})$.

Definition We will use the following symbols as operational analogs: for creation $\mathrm{V}$ (disjunction), for iteration $-\&$ (conjunction). In the traditional symbol form we therefore get: $\&(\mathrm{p}) \div \mathrm{I} ; \mathrm{V}(\mathrm{p}) \div \mathrm{H}$

Commentary. Here we must say that the notion of "one and the same letter," i.e. something that is characterized by the word "one," has not been explained. To overcome this difficulty we will have to revert to additional philosophical and methodological aberrations: Let us ask ourselves: are the word "one" and the word combination "one and the same" synonymous? We believe that the quantitative content of this word is secondary. "One" is first and foremost a characteristic of qualitative uniqueness in the world of real-life subjects, which had had no independent quantitative meaning. But the qualitative uniqueness had initially been relative: the differences were originally not classed at 
all - they just existed! In the future we will use the notion of "same letters" to denote qualitative specifics of the first root. For instance, we will consider words q, qq, sss, etc.as consisting of same letters. This corresponds fully to the notion of a random letter as continuation of something uttered earlier. Consequently,as opposite to the notion of "same letters" we will offer the notion of "different letters" (that is, chains of qpq,sq...), and not "multiple letters," since the latter has a precisely defined quantitative shade of meaning. We must note also that we cannot introduce the logical denial of both properties by allowing the notion of "no letters" due to its internal contradictory nature. As a consequence we hypothesize that there is no mechanism for negating a speech act in the language, As any other operator, negation is applicable only to something definite, to particular cases of linguistic behavior (a pause in speaking is a particular case of speaking, an element of speech behavior strategy).

Now we will reassess the traditional notion of forms of thought that the logical (logico-mathematical) syntax deals with: if $p$ is a traditional form of thought, then $p$ is the continuation of the speech act; if $p$ is some sort of continuation then $p$ has a predecessor; in relation to the preceding act $\mathrm{p}$ acts as a result, or meaning (meaningful outcome) of this speech act.

Since any result is either different from the precedent act (creation) or something similar to it (iteration), then we can say that $\mathrm{p}$ is either $\mathrm{H}$ or I. The pair $<$ H,I $>$ denotes the area of meaning of some speech acts as related to others. As a result of precedent linguistic acts, p presupposes continuation. This continuation can take the form of creation or iteration. Using \& and V operators we will obtain two possible variants of continuing $\mathrm{p}$ as $\mathrm{V}(\mathrm{p})$ and $\&(\mathrm{p})$.

One should not think that any two possible speech act continuations are always alternative to each other. We can express the situation of alternativeness of $\&$ and $\mathrm{V}$ only as related to some exact certainty. This variable is represented in our case as "I".

As we have said before, iteration is related to sameness, which allows to define an arbitrary "something" as the same. Iteration in this sense is simply an act-based analog of the idempotent law (the principle of objectified activity dualism). Therefore, we can introduce the alternative of

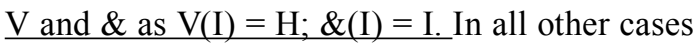
the alternativeness of $\mathrm{V}$ and $\&$ is not present.

This is represented in Table A:

\begin{tabular}{|l|c|c|}
\hline $\mathrm{F}(\mathrm{p})$ & $\mathrm{H}$ & $\mathrm{I}$ \\
\hline $\mathrm{V}(\mathrm{p})$ & $\mathrm{H}$ & $\mathrm{H}$ \\
\hline$\&(\mathrm{p})$ & $\mathrm{H}$ & $\mathrm{I}$ \\
\hline
\end{tabular}

We have thereby introduced the principle of objectified activity dualism: anything that is declared as continuation of speaking has some objective meaning or some result in relation to precedent acts, and simultaneously it is the activity that constitutes the subsequent something, i.e. an operational act.

Let us therefore agree that $\&$ and $\mathrm{V}$ operators can be viewed as connectors, considering that connected speech acts represent a particular case of continued speech behavior. Therefore: $\mathrm{V}(\mathrm{I})=\mathrm{I}$ $\mathrm{V} \mathrm{I}=\mathrm{H} ; \&(\mathrm{I})=\mathrm{I} \& \mathrm{I}=\mathrm{I}$. Consequently, I V H = I $\& \mathrm{H}=\mathrm{H} \mathrm{V} \mathrm{H}=\mathrm{H} \& \mathrm{H}=\mathrm{H}$ and we arrive at Table $\mathrm{B}$ :

\begin{tabular}{|c|c|c|}
\hline $\mathrm{p} \mathrm{q}$ & $\mathrm{p} \mathrm{Vq}$ & $\mathrm{p} \& \mathrm{q}$ \\
\hline $\mathrm{I} \mathrm{I}$ & $\mathrm{H}$ & $\mathrm{I}$ \\
\hline $\mathrm{I} \mathrm{H}$ & $\mathrm{H}$ & $\mathrm{H}$ \\
\hline $\mathrm{H} \mathrm{I}$ & $\mathrm{H}$ & $\mathrm{H}$ \\
\hline $\mathrm{H} \mathrm{H}$ & $\mathrm{H}$ & $\mathrm{H}$ \\
\hline
\end{tabular}

Here we would like to turn our readers' attention to the fundamental meaning of the OAD principle as shown in Table B. According 
to this principle, neither the accidental similarity of some speech act to something pronounced before (as symbolized by I), nor the very fact of existence of various alternative ways of continuing speaking (\&/v) allow for sufficient conditions for appearance of iteration (stable uniformity of linguistic acts). We can achieve this effect only by superpositioning the subject (I) and activity (\&) components, which are variable in themselves (linguistic activity is not limited by anything) .

Every notion that we have introduced so far is no more than representation of the image of the linguistic element using the symbols logicians are used to. It is easy to understand that existence of one and the same speaking pattern (I) does not undermine or devalue the aforementioned elemental character of the event. More than that, this principle develops and enriches the content further, since in addition to the element of creation we now have the element of iteration, too!

Our next goal is to turn the element of iteration into a habitual skill. The notion of skill in logic is often expressed in numeration. Therefore, we will need a system of figures of consequence that will allow us to obtain only I-formulas in the denominator. Naturally, this numeration must be logically correct, uncontradictory; i.e. it should be, in some way or another, a private case of enumerating logical tautologies, i.e. identically true formulas of propositionary logic. We will not tire our readers by providing a detailed description of this scheme. You can find more information on this in (Cherepanov, 2004), where the process of enumerating So and its continuation are described.

Conclusions. Methodological provisions that allow to actualize the possibility of language theorizing (and first and foremost the acts of naming) are formulated as three principles: the principle of informativity of naming acts, the principle of non-self sameness of signs and the principle of objectified activity dualism.

The theory of names is seen as a sequence of three construction stages: At the first stage the initial language elements related to $\{\mathrm{H}, \mathrm{I}\}$ pair is defined, where $\mathrm{H}$ stands for words with different letters, and I - for words with repeating letters. At the second stage empty words are introduced and the typology of words expands to $\{\mathrm{H}, \mathrm{I}, \varnothing\}$; the semantic model of word (wordletter) combinations are defined as in Table B (in extended by a negation operation" “" and " $\varnothing ")$. At the third stage built the Calculus (So) allows to recreate all variants of obtaining I-words as defined by the aforementioned semantics. The presentation of "calculation same-letteredness" (So) testifies to the fact that iteration ceases to be a random event in the process of creating letters (sounds) and becomes a stable phenomenon (proof of So). This is enough to ascertain the occurrence of the tradition of language behavior. Later would be called a naming.

\section{Reference}

1. Cherepanov S. Philosophy of indefinity: indefinity and paradoxes. Novosibirsk, 2004. [Philosophiia neopredelennosti: neopredelennost i paradoksy. Novosibirsk, 2004. 178 s.]

2. Dennet D. Real Patterns. Journal of Philisophy, 1991, vol. 89, p. 27-51.

3. Dummett M. What is a Theory of meaning? Essays in Semantics. (1976), Oxford, p. 87-137.

4. Field H. Theory Change and Indeterminacy // Journal of Philosophy. 1973, vol. 70, p. 200228.

5. Hintikka Y. Logic, language-games and information. Kantian thems in the philosophy of logic. Oxford, 1973, X, $291 \mathrm{p}$.

6. Kripke S. Naming and Necessity. Cambridge, 1980, p. 48. 
7. Kuslii P. The Reference function of name Logos (2009), 2(70), p. 67-84. [Referecionalnaia funkciia imen - Logos (2009), 2(70), s.67-84]

8. Laguta O. Logic and Linguistic. Novosibirsk, 2007. 158 p. [Logika i lingvistika. $158 \mathrm{~s}$ ]

9. Levin A Modern Tendency of the development of semiotics [Sovremennii tendencii razvitija semiotiki (obzor) - Logika i metodologija nauki II] 1975. S. 83-116.

10. Russell B. On Denotion - Mind (1905), vol. 14, p. 479-493.

11. Vopenka P. Úvod do matematiky v alternatívnes teórii množin. Bratislava, 1989. $589 \mathrm{~s}$.

12. Wright, von. G The Heterological paradox Philosophical papers, (1984), vol. 3, [Vrigt G. Logiko-filosofskie issledovaniia. M., 1986. 590 s.].

\title{
Методологические проблемы исследования номинаций в искусственных языках
}

\author{
С.К. Черепанов ${ }^{a}$, Ю.П. Роговой \\ ${ }^{a}$ Сибирский федеральный университет \\ Россия, 660041, Красноярск, пр. Свободный, 79 \\ ${ }^{6}$ Санкт-Петербургский национальный \\ исследовательский университет \\ информационных технологий, механики и оптики \\ Россия, 197101, Санкт-Петербург, пр. Кронверкский, 49
}

\begin{abstract}
На основании разграничения понятий «язык» и «форма мысли» вводится представление о домыслительном состоянии языка в виде стихии индивидуального звукотворчества (буквопорождения). Исходя из традиционного представления об эволюиии языка в направлении обуздания индивидуальной стихии посредством социальных норм языкового поведения, обрисовывается вариант логической экспликации такой эволюиии. Формулируются методологические принщипы, на базе которых упомянутая экспликация может быть реализована в виде некоторой «теории имен».
\end{abstract}

Ключевые слова: искусственный язык, домыслительная стадия эволючии языка, буквопорождение, логическая экспликаџия, номинация, индивидуальная стихия говорения. «теория имен».

Научная спеииальность: 09.00.00 - философские науки. 